\title{
Fostering viability and sustainability of small and medium enterprises: Determining the true beneficiaries of university research output
}

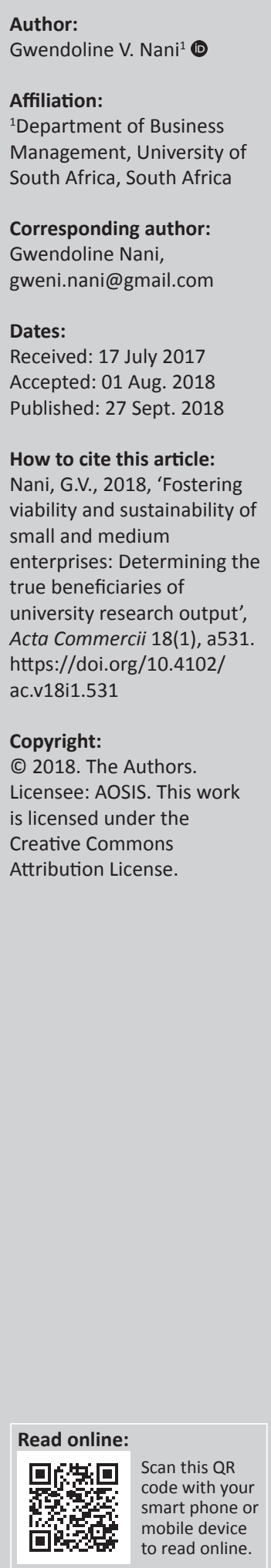

Orientation: The focus of this study was dissemination of university research output to small and medium enterprises.

Research purpose: This study sought to determine the true beneficiaries of research output.

Motivation of the study: Situations occur where research was conducted, but the purported beneficiaries did not receive feedback.

Research design, approach and method: A case survey approach involving 80 lecturers from the Faculty of Commerce of one public university in Zimbabwe was utilised. Semi-structured questionnaires were used to elicit responses from academic researchers. Analysis of quantitative data was done through frequencies, percentages, cross tabulations and Pearson chi-square tests. Qualitative data were analysed thematically.

Main findings: The findings revealed that only $36.92 \%$ had conducted studies on small and medium enterprises (SMEs), while the remaining 63.08\% had conducted other studies not related to SMEs. Out of the $36.92 \%$ of the respondents who had conducted studies on SMEs, $41.67 \%$ had not disseminated their results to the targeted beneficiaries. The study concluded that dissemination of research output for practical use seemed not to be a priority for some academic researchers. Non-distribution of results by academics indicated underlying challenges.

Practical/managerial implications: The study recommended that researchers should be reminded of the importance of conveying their findings for practical use and responsible authorities should encourage the dissemination of research output through the provision of incentives and support systems.

Contribution/value-add: The study identified a dearth of research on who benefits if research studies are conducted on SMEs but the results are not disseminated to them and thus attempted to address this gap.

\section{Introduction and background}

Globally, universities have been regarded as institutions that create knowledge through research activities (Brennan, King \& Lebeau 2004:7; Mutwiri 2014:1) and they also serve as conduits for the transfer, adaptation and dissemination of generated knowledge (Kavulya 2004:3). Okonofua (2008) cited in Nwabueze et al. (2010:1) concurs that research is essential to a university's mission as it helps the university provide special services to its immediate community. McGrath (2016:3) regards sharing of research output as a crucial part of making sure your work has an impact outside your organisation. A researcher puts a huge amount of effort into conducting research; therefore, there is a need for the effort to be rewarded. Research work is valuable and can transform practice and lives only when the findings are shared with people who can use them to change policy and practice. Merriam and Tisdell (2016:290) concur that without the important step of reporting and disseminating results, the research process would be incomplete. Turale (2011:2) further contends that it is unethical to conduct research studies but fail to appropriately disseminate findings.

The question then becomes, 'What is meant by dissemination of research output?' According to Bauman et al. (2017:1), dissemination is a systematic process through which information messages are distributed and shared, and by which intended audiences receive, accept and utilise the information. Wilson (2010) cited in Macoubrie and Harrison (2013) explains dissemination as a: 
planned process that involves consideration of target audiences and the settings in which research findings are to be received, and where appropriate, communicated in ways that will facilitate research uptake in decision making processes and practice. (p. 5)

Lokkegaard (2018:31) explains dissemination as not only to send but also to receive; and to receive is not only to physically or virtually access something, but also to understand it, find it relevant and be capable of using it. To disseminate scientific knowledge successfully to small and medium enterprises (SMEs) means to make clear how knowledge can be used in practice. Therefore, in this study, dissemination referred to planned communication to make research functional through engagement of the intended beneficiaries, taking into cognisance the targeted audience (the SMEs), capabilities and capacities.

In every research study, intended beneficiaries are mentioned implying that these are the people for whom the research studies are conducted. However, in the absence of communication of the findings to the targeted beneficiaries, in a way that will make the information practicable, one wonders who the real beneficiaries are. This is the question that formed the motivation for this study as the bigger study on fostering viability and sustainability of SMEs through research output exposed that research studies had been conducted on various aspects of SMEs by respondents in a selected university, but some of the researchers had not conveyed the findings to the intended beneficiaries. What further buttressed the need for conducting this study were the concerns raised by the then Minister of Higher and Tertiary Education, Science and Technology as quoted by Tshili (2015) that most of Zimbabwe's academics were failing to make an impact on developmental issues. According to Oronje (2006:78), university research identifies, quantifies societal challenges and can even suggest strategies in solving the identified problems. Without research, it becomes difficult to solve problems because of lack of relevant information on the causes, the extent and the possible ways of addressing them. However, Stepherson, Calda and Javier (2014:31) argue that instead of research results being put into practical use by beneficiaries, they have ended up in the libraries because of lack of dissemination strategies. Oronje (2006:78) concurs that a great amount of money is spent on generating knowledge through research which most of the time ends up on library shelves, not only inaccessible to many of the mentioned audience; but also contained in not easy-to-use formats.

Literature review revealed research studies that have been conducted on various aspects of SMEs in Zimbabwe (Gombarume \& Mavhundutse 2014:103; Munanga 2013:377; Tinarwo 2016:148) among others, but none of the accessed studies had focused on dissemination of research output. Suggested methods of improving viability and sustainability of SMEs can only be implemented if recipients have access to output. Bearing in mind that SMEs are regarded as the cornerstone for employment creation and poverty alleviation in Zimbabwe, the author did not access any studies which focused specifically on who benefits if research studies are conducted on SMEs but the results are not disseminated to them, hence this study. Therefore, the research objectives in the current study attempted to address the dearth in the literature on dissemination of output studies identified in Zimbabwe.

This study was meant to conscientise and remind researchers, in general, and academics of the selected university, in particular, of their ethical obligation to disseminate data to the respondents from whom they would have collected the data. The majority of respondents participate with the hope that these studies would transform their businesses, but in the absence of feedback, that hope is dashed. A research study on dissemination of research output would inform not only university funders but also policymakers of the suggested recommendations for the betterment of businesses in a developing country like Zimbabwe.

\section{Research objectives}

The primary objective of the study was to establish who the true beneficiaries of research output were in the event of nondissemination of results to SMEs for practical use.

The following secondary objectives assisted in the achievement of the primary objective.

- To ascertain the reasons for conducting research studies on SMEs by lecturers who had not disseminated their results.

- To establish the reasons for non-dissemination of results to beneficiaries and what the lecturers intended to do with their research output.

- To establish the level of awareness of the importance of communicating research results by lecturers who had not disseminated their results.

\section{Literature review}

Knowledge dissemination continues to be a focus point and it has become a strategic issue as a source of funding for university research and as a policy tool for economic development (Geuna \& Muscio 2009:93). Kavan (1998) cited in Lang (2003:3) concurs that knowledge created but not shared has no value. However, efforts to ensure that scientific knowledge reaches the most appropriate audience, in the most appropriate form, and in a timely manner, are largely absent. In countries such as Denmark, by 2003, Danish universities were required by law to share their knowledge with business, thereby making the dissemination of scientific knowledge a government demand rather than a voluntary scientific activity (Lokkegaard 2018:19-20). In a study on 'Challenges faced by the African Population and Health Research Centre', Oronje (2006:80) found out that communication and dissemination activities were not given adequate priority compared to research activities (knowledge generation).

As previously highlighted, researchers nominate intended beneficiaries of their research output but certain factors might 
influence their dissemination practices and these include funding bodies, pressure to get promotion, professional bodies and the reputation of the journal (Fry et al. 2009:26, 58). In a study by Panda and Gupta (2014:8-9) on 'making academic research more relevant in India', it was established that academic scholars seemed to find themselves caught between the need to conduct context-sensitive research and the need to publish in reputed peer-reviewed journals to ensure enhancement of their professional reputation and the ranking of their business schools. However, the review processes of these peer-reviewed journals tended to emphasise methodological rigour rather than organisational relevance.

Lokkegaard (2018:283) asserts that researchers are rewarded for research and teaching, and only to a lesser extent for disseminating their results to the public. A study on 'disseminating scientific knowledge to small and medium sized enterprises', by the aforementioned author, exposed that Danish researchers are awarded for publications and not for transforming the results into popularised news or practice oriented how-to manuals. Consequently, the willingness to engage in dissemination activities is not necessarily present. Disseminating scientific knowledge to society has historically not been part of the researcher's job description which means that they are not obliged to spend time on it, as it is not explicitly their duty. However, change is happening as more and more researchers are encouraged to inform society about what they are doing.

According to Khatri et al. (2012) in Panda and Gupta (2014:8-9), research in India may be related to publishing pressures for tenure and reputation in the context of a researcher's country of employment and not out of genuine curiosity to explore and understand management in India. Sweeny (2000) cited in Mutwiri (2014:2) alludes to the aforementioned that publications of research findings in established traditional refereed journals have been one of the criteria used by universities to promote their academic staff.

Promotion in Zimbabwean universities is dependent on, among other criteria, research output. However, regulations do not specify that an academic should not only have authored but should also have disseminated those findings to the intended beneficiaries for implementation. Of course, some academics will argue that their findings are either online or in libraries and might further argue that it is not mandatory for them to make follow-ups on the uptake of the findings. One may also argue to say if the research was conducted in the name of wanting to positively contribute towards the named beneficiaries, then the dissemination should also be the researcher's concern.

As previously stated, some of the reasons that compel researchers to publish are institutional. A study by Fry et al. (2009:15) on 'how and why researchers publish and disseminate research findings' revealed that there was a clear opinion that outputs of greatest importance to institutions were papers in peer-reviewed journals. These results imply that the reputations of both the journal and the institution are boosted through the publication of high-quality articles that undergo peer review processes. Brennan et al. (2004:16) assert that the common forms of communication channels used by researchers are conference presentations, workshops, books and reports which Lang (2003:3) and Panda and Gupta (2014:2) critique by saying these channels are beyond the reach of particularly SME owners because of the rigour employed by academics in the dissemination of results.

Turale (2011:1) asserts that a big problem in research today is the research practice gap, often caused by non-dissemination of new knowledge from research and translation into practice. Only a small percentage of research results are translated into practice because results may not be disseminated at all; findings are not disseminated to the right audiences or results are disseminated but are not translated into practice. Lokkegaard (2018:186) concurs that universities generate knowledge that is not usable because it is not practicable. A university develops theoretical knowledge perceived as too technical by SMEs. According to Bouazza (2015:1), SMEs are acknowledged globally for their unique contribution to economic development and creating employment opportunities. In both developed and developing countries, SMEs have been regarded as one of the key instruments to use to face economic and social problems and to achieve developmental objectives. Kongolo (2010:2288) agrees that SMEs have historically played an important role in contributing to economic development of many countries around the world. In this regard, Lokkegaard (2018:145) opines that in order for SMEs to be able to implement scientific knowledge to their own situations, SMEs need knowledge that is easily and quickly accessible, personalised, experience based, specific and cost-effective. They need scientific knowledge to be practically oriented to solve specific needs rather than theoretical. According to Turale (2011:1), it is important to think about why a particular piece of research is being conducted and it is also critical to share research findings appropriately to audiences to help them translate findings into practice. Sharing research findings can open doors to many possibilities that lead to the well-being of members of communities.

\section{Methodology Research design}

The study was confined to establishing reasons for conducting research if results are not going to be disseminated to intended beneficiaries. This was examined through an empirical case survey approach of one public university in Zimbabwe. According to Bryman et al. (2017:110), a case study involves the detailed and intensive analysis of one or more cases which the researcher aims to study in depth. A case can be a single organisation. The most common use of the term 'case' associates the case study with a geographic location, such as a workplace or organisation. What distinguishes a case study from other designs is the focus on understanding a bounded situation. A case study researcher usually seeks to highlight the unique features of the case. 
Stake (1995) cited in Bryman et al. (2017:111) distinguishes between different types of case studies. This particular case is the intrinsic case study that was undertaken primarily to gain insight into the particularities of a single situation, rather than to gain insight into other cases or generic issues. This is why the study was conducted in this particular university. By being specific, the researcher wanted to give the study an identity and a purpose through the study of a particular segment of the population. The results from this study were meant to establish the situation in the selected university first before embarking on a comparative study. Results from this study would then inform a comparative study with other universities.

The study adopted a mixed method design though with a bias towards a qualitative approach because of the nature of the questions which were mostly open-ended. Qualitative data were collected through open-ended questions on issues of viability and sustainability of SMEs and when and how research output could be made beneficial. The justification for including open-ended questions was to get enriched detail which closed questions characteristic of quantitative studies would not provide (Cooper \& Schindler 2008:339). Quantitative data were obtained through five-point Likertscale type questions. These questions sought to solicit data on reasons why lecturers had conducted studies on SMEs; reasons for non-dissemination of research output for practical use and what lecturers intended to do with their research output. These questions were meant to investigate who the true beneficiaries for this study were in the case of results that had not been disseminated.

\section{Population and sample}

The population for this study consisted of 99 lecturers (excluding those on leave) in the Faculty of Commerce of one selected public university in Zimbabwe. From a population of 99 academics obtained from the internal staff directory of the selected university, the appropriate sample size according to Krejcie and Morgan's (1970:607-610) table for determining the sample size was 80 . The lecturers were selected from the Departments of Accounting, Banking, Finance, Business Management, Marketing, Insurance and Actuarial Science, the Graduate School of Business and the Institute of Development Studies, using a two-stage sample design. The first stage consisted of proportionate sampling, while the second stage involved randomly selecting the lecturers for questionnaire distribution using simple random sampling (SRS). The justification for the inclusion of the lecturers was that they were the ones who generated the research output.

\section{Data collection methods}

The researcher developed the questionnaire which was used for data collection. The survey questions were derived from the variables in the topic under study. Questions included structured (closed response, specified alternatives provided) and unstructured (open-ended) types. Free response questions allowed the respondents to express themselves extensively while with the structured questions, respondents' latitude was restricted by space, layout or instructions to choose one word or fill-in (Cooper \& Schindler 2008:339). The aim was to get coverage of as many respondents as possible and collect as much data as possible (Bryman 2012:233). Questionnaires are ideal in this regard though when it comes to gaining in-depth data, they fall short hence the inclusion of open-ended questions. Before the actual data collection, questionnaires were pre-tested and pilot-tested for reliability and ambiguity by fellow academics and corrections were made accordingly. To test the content and construct validity, the questionnaire was examined to find out whether all the aspects that it was intended to measure were addressed.

Data collection by the researcher took 2 months as the lecturers were busy with the processing of examinations and results. Seventy-five semi-structured questionnaires were personally distributed by the researcher and five were posted on the Internet. From the 80 distributed questionnaires, $81.25 \%$ were retrieved.

\section{Data analysis}

For quantitative data, the exercise started off with the cleaning of the data for completeness and usability. All the questionnaires were found to be suitable for analysis. Quantitative data were then analysed through frequencies and percentages with the use of the Statistical Package for Social Sciences (SPSS) and presentation was in the form of tables. Cross tabulations between demographic variables and questions specifically related to non-disseminated data were conducted to find out if there were relationships. Pearson chisquare tests were also performed to establish whether there were any significant relationships between demographic variables and selected questions at 0.05 level of significance. For the qualitative part of the study, data were analysed according to themes which emerged after the data had been labelled and grouped according to similarities. The emerging themes were then interpreted in the context of the objectives of the study. Direct quotations were also used to present this data. In this study, the terms respondents, academics, lecturers and participants were used interchangeably. From the $81.25 \%$ collected questionnaires, only $36.92 \%$ had conducted studies on SMEs, while the remaining $63.08 \%$ had conducted other studies not related to SMEs. Out of the $36.92 \%$ of the respondents who had conducted studies on SMEs, $41.67 \%$ had not disseminated their results and these are the respondents who formed the basis of this study.

\section{Ethical considerations}

All research studies attract ethical implications and this study had to comply. Ethical considerations are meant to protect respondents from harm and any form of risks as well as to address the issues of informed consent, anonymity and invasion of privacy, among other concerns (Bryman 2012:135-143). In this regard, ethical clearance was obtained from the institution with which the researcher was attached (Ref. 2016_CRERC_021(SD); after which permission to 
conduct the study was sought from the public university under consideration in Zimbabwe (Ref.FM/sb 13/12/2016). Lecturers who were the respondents in this study were individually approached for voluntary consent to participate in the study. The process entailed explaining to the respondents the purpose of the study and their freedom to withdraw without suffering any penalty.

\section{Discussion and conclusion Discussion on the analysis of demographic variables}

The purpose of this article was to establish who the true beneficiaries of research output were in a situation where research studies were conducted but not all the purported recipients had received the results for implementation. The results were discussed in light of the important role shown in the literature by universities in generating data to enhance the operations of businesses. The discussion was preceded by cross tabulations of demographic variables with selected questions on the dissemination of output to examine the patterns of interrelations among the questions. Pearson chi-square tests were also conducted to test whether there were any significant relationships between the demographic variables and the selected questions at $p$-value of 0.05 , the level of significance.

The findings are presented in Tables 1-6. Table 1 presents the demographic composition of the total number of respondents who had conducted research studies on SMEs. Table 2 portrays the areas of focus of the respondents who had conducted research studies on SMEs. In Table 3, the intended beneficiaries of respondents who had conducted studies on SMEs but had not communicated their results are shown. Reasons for nondissemination of findings by the respondents are presented in Table 4 . Table 5 presents the location of the unpublished results. Table 6 provides the intentions of the respondents who had not published their studies. It is from these results that inferences were drawn. It is important to note that the respondents could pick more than one option or could not pick any option at all; hence, some of the frequencies do not add up to the total number of participants who did not disseminate their findings.

Results in Table 1 show more young lecturers in the age group of 31-40 years compared to the 51 and above group. Such an institution is bound to have more research work that can address the challenges faced by SMEs based on the assumption that the younger the more creative and innovative. There are also more Master's degree than $\mathrm{PhD}$ holders. Although the number of young lecturers could suggest potential for more research, the few PhD holders in this university could imply lack of high-impact research work based on the perceptions that the more senior the lecturers are, the more experience they have in research. The involvement by all departments in the Faculty of Commerce in this university was meant to garner cross pollination of ideas on the viability and sustainability of SMEs. However, the low output by researchers who inform the industry is a cause for concern.
Based on the results in Table 2, the researchers had focused on crucial areas in the viability and sustainability of SMEs such as failure and successes of SMEs, challenges faced by SMEs, the business environment and SMEs, SMEs financing and business integration. There were more men than women, more age groups of 31-40, more Master's than PhD holders and more permanent full time lecturers who had focused on these areas. However, the low output gives the impression of lack of intensity and coverage of matters to do with viability and sustainability of SMEs.

Table 3 shows that the targeted beneficiaries were the most relevant people in the industry, the SME owners and policymakers. One would assume that if policymakers are made aware of issues pertaining to SMEs, a conducive environment can be created for viability and sustainability. However, this can only be achieved if the research output is disseminated.

One area pertinent to this study was who the true beneficiaries were when respondents did not get feedback. Table 4 shows that the following had not conveyed their results for

TABLE 1: Demographic composition of respondents who did studies on small and medium enterprises $(N=24)$.

\begin{tabular}{|c|c|c|}
\hline Demographic variable & Frequency $(n)$ & Percent (\%) \\
\hline \multicolumn{3}{|l|}{ Gender } \\
\hline Male & 18 & 75.00 \\
\hline Female & 6 & 25.00 \\
\hline Total & 24 & - \\
\hline \multicolumn{3}{|l|}{ Age range } \\
\hline 20 or younger & 1 & 4.17 \\
\hline $21-30$ & 2 & 8.33 \\
\hline $31-40$ & 12 & 50.00 \\
\hline $41-50$ & 5 & 20.83 \\
\hline 51 and above & 4 & 16.67 \\
\hline Total & 24 & - \\
\hline \multicolumn{3}{|l|}{ Highest level of education } \\
\hline Master's & 20 & 83.33 \\
\hline $\mathrm{PhD}$ & 4 & 16.67 \\
\hline Total & 24 & - \\
\hline \multicolumn{3}{|l|}{ Academic ranking } \\
\hline Lecturer & 18 & 75.00 \\
\hline Senior lecturer & 2 & 8.33 \\
\hline Research fellow & 4 & 16.67 \\
\hline Total & 24 & - \\
\hline \multicolumn{3}{|l|}{ Type of employment } \\
\hline Permanent full time & 17 & 70.83 \\
\hline Temporary full time & 4 & 16.67 \\
\hline Contract & 3 & 12.50 \\
\hline Total & 24 & - \\
\hline \multicolumn{3}{|l|}{ Department } \\
\hline Business management & 5 & 20.83 \\
\hline Marketing & 1 & 4.17 \\
\hline Banking & 3 & 12.50 \\
\hline Finance & 5 & 20.83 \\
\hline Insurance \& Actuarial Science & 2 & 8.33 \\
\hline Accounting & 2 & 8.33 \\
\hline IDS & 4 & 16.67 \\
\hline GSB & 2 & 8.33 \\
\hline Total & 24 & - \\
\hline
\end{tabular}

IDS, Institute of Development Studies; GSB, Graduate School of Business. 
TABLE 2: Areas of focus by all who conducted studies on small and medium enterprises, based on demographic variables $(N=14)$.

\begin{tabular}{|c|c|c|c|c|c|c|c|c|c|c|c|c|}
\hline \multirow{2}{*}{$\begin{array}{l}\text { Demographic } \\
\text { variable }\end{array}$} & \multicolumn{2}{|c|}{ Failure of SMEs } & \multicolumn{2}{|c|}{ Successes of SMEs } & \multicolumn{2}{|c|}{ Challenges faced by SMEs } & \multicolumn{2}{|c|}{ Business environment and SMEs } & \multicolumn{2}{|c|}{ SMEs finance } & \multicolumn{2}{|c|}{ Business integration } \\
\hline & Frequency & Percentage & Frequency & Percentage & Frequency & Percentage & Frequency & Percentage & Frequency & Percentage & Frequency & Percentage \\
\hline \multicolumn{13}{|l|}{ Gender } \\
\hline Male & 4 & 28.57 & 4 & 28.57 & 9 & 64.29 & 4 & 28.57 & 1 & 7.14 & 1 & 7.14 \\
\hline Female & 2 & 14.29 & 2 & 14.29 & 5 & 35.71 & 2 & 14.29 & 0 & - & 0 & - \\
\hline Total & 6 & - & 6 & - & 14 & - & 6 & - & 1 & - & 1 & - \\
\hline \multicolumn{13}{|l|}{ Age range } \\
\hline 20 or younger & 0 & - & 0 & - & 1 & 7.14 & 0 & - & 0 & - & 0 & - \\
\hline $21-30$ & 0 & - & 0 & - & 0 & - & 2 & 14.29 & 0 & - & 0 & - \\
\hline $31-40$ & 5 & 35.71 & 3 & 21.43 & 8 & 57.14 & 3 & 21.43 & 1 & 7.14 & 0 & - \\
\hline $41-50$ & 0 & - & 2 & 14.29 & 3 & 21.43 & 0 & - & 0 & - & 1 & 7.14 \\
\hline 51 and above & 1 & 7.14 & 1 & 7.14 & 2 & 14.29 & 1 & 7.14 & 0 & - & 0 & - \\
\hline Total & 6 & - & 6 & - & 14 & - & 6 & - & 1 & - & 1 & - \\
\hline \multicolumn{13}{|c|}{ Highest level of education } \\
\hline Master's & 6 & 42.86 & 6 & 42.86 & 10 & 71.43 & 5 & - & 0 & - & 1 & 7.14 \\
\hline $\mathrm{PhD}$ & 0 & - & 0 & - & 4 & 28.57 & 1 & - & 0 & - & 0 & - \\
\hline Total & 6 & - & 6 & - & 14 & - & 6 & - & 0 & - & 1 & - \\
\hline \multicolumn{13}{|l|}{$\begin{array}{l}\text { Academic } \\
\text { ranking }\end{array}$} \\
\hline Lecturer & 3 & 21.43 & 1 & 7.14 & 9 & 64.29 & 4 & - & 1 & 7.14 & 1 & 7.14 \\
\hline Senior lecturer & 0 & - & 2 & 14.29 & 2 & 14.29 & 0 & - & 0 & - & 0 & - \\
\hline $\begin{array}{l}\text { Research } \\
\text { fellow }\end{array}$ & 3 & 21.43 & 3 & 21.43 & 3 & 21.43 & 2 & - & 0 & - & 0 & - \\
\hline Total & 6 & - & 6 & - & 14 & - & 6 & - & 1 & - & 1 & - \\
\hline \multicolumn{13}{|c|}{ Type of employment } \\
\hline $\begin{array}{l}\text { Permanent full } \\
\text { time }\end{array}$ & 4 & 28.57 & 4 & 28.57 & 13 & 92.86 & 3 & - & 1 & 7.14 & 1 & 7.14 \\
\hline $\begin{array}{l}\text { Temporary full } \\
\text { time }\end{array}$ & 1 & 7.14 & 1 & 7.14 & 0 & - & 1 & - & 0 & - & 0 & - \\
\hline Contract & 0 & - & 0 & - & 0 & - & 0 & - & 0 & - & 0 & - \\
\hline Total & 5 & - & 5 & - & 13 & - & 4 & - & 1 & - & 1 & 7.14 \\
\hline \multicolumn{13}{|l|}{ Department } \\
\hline $\begin{array}{l}\text { Business } \\
\text { management }\end{array}$ & 2 & 14.29 & 2 & 14.29 & 2 & 14.29 & 0 & - & 0 & - & 0 & - \\
\hline Marketing & 0 & - & 0 & - & 1 & 7.14 & 0 & - & 0 & - & 0 & - \\
\hline Banking & 1 & 7.14 & 0 & - & 1 & 7.14 & 0 & - & 1 & 7.14 & 1 & 7.14 \\
\hline Finance & 1 & 7.14 & 0 & - & 4 & 28.57 & 0 & - & 0 & - & 0 & - \\
\hline $\begin{array}{l}\text { Insurance \& } \\
\text { Actuarial } \\
\text { Science }\end{array}$ & 0 & - & 0 & - & 1 & 7.14 & 1 & - & 0 & - & 0 & - \\
\hline Accounting & 0 & - & 0 & - & 0 & - & 2 & - & 0 & - & 0 & - \\
\hline IDS & 2 & 14.29 & 2 & 14.29 & 2 & 14.29 & 2 & - & 0 & - & 0 & - \\
\hline GSB & 0 & - & 2 & 14.29 & 2 & 14.29 & 0 & - & 0 & - & 0 & - \\
\hline Total & 6 & - & 6 & - & 13 & - & 5 & - & 1 & - & 1 & - \\
\hline
\end{tabular}

Note: Respondents could choose more than one option, or none at all; hence, the results do not tally with $N=14$.

IDS, Institute of Development Studies; GSB, Graduate School of Business; SME, small and medium enterprise.

implementation, more male respondents, and more respondents in the age group of 31-40, more Master's holders and more permanent full time lecturers. The lecturers had fulfilled the mandate by universities that of generating knowledge (Brennan et al. 2004:7; Mutwiri 2014:1) but had not communicated it as postulated by McGrath (2016:3) and Merriam and Tisdell (2016:290). In such a scenario, SMEs are bound to continue facing similar challenges.

Table 5 shows the different places where non-disseminated research output was located. More men than women had their studies in their offices and online than women. Respondents in the age group of 31-40 who would have been expected to be more interactive had not disseminated their results. Results showed a significant relationship (0.003) between the age range and the location of respondents' work. More researchers with a Master's qualification had conveyed their output online than their PhD counterparts. These results show a growing trend towards publishing online as opposed to the traditional forms of dissemination such as conference presentations, workshops, books and reports (Brennan et al. 2004:16; Mutwiri 2014:3). Still, online publications could be beyond the reach of SME owners in a developing country like Zimbabwe with challenges of network connectivity. Besides, Lang (2003:3) and Panda and Gupta (2014:2) argue that these channels are beyond the reach of SME owners because of the rigour employed by academics in their research work.

Turale (2011:1) asserts that it is important to think about why a particular piece of research is being conducted and it is also critical to share research findings appropriately to audiences to help them translate findings into practice. So, if researchers 
TABLE 3: Respondents' beneficiaries of only those who did not disseminate their results $(N=10)$.

\begin{tabular}{|c|c|c|c|c|c|c|}
\hline \multirow[t]{2}{*}{ Demographic variable } & \multicolumn{2}{|c|}{ Owners of SMEs } & \multicolumn{2}{|c|}{ Policymakers } & \multicolumn{2}{|c|}{ Donor community } \\
\hline & Frequency & Percentage & Frequency & Percentage & Frequency & Percentage \\
\hline \multicolumn{7}{|l|}{ Gender } \\
\hline Male & 8 & 80 & 6 & 60 & 4 & 40 \\
\hline Female & 2 & 20 & 4 & 40 & 0 & - \\
\hline Total & 10 & - & 10 & - & 4 & - \\
\hline \multicolumn{7}{|l|}{ Age range } \\
\hline $21-30$ & 2 & 20 & 0 & - & 0 & - \\
\hline $31-40$ & 4 & 40 & 8 & 80 & 0 & - \\
\hline $41-50$ & 1 & 10 & 0 & - & 4 & 40 \\
\hline 51 and above & 2 & 20 & 2 & 20 & 0 & - \\
\hline Total & 10 & - & 10 & - & 4 & - \\
\hline \multicolumn{7}{|l|}{ Highest level of education } \\
\hline Master's & 6 & 60 & 9 & 90 & 4 & 40 \\
\hline Total & 9 & - & 10 & - & 4 & - \\
\hline \multicolumn{7}{|l|}{ Academic ranking } \\
\hline Lecturer & 10 & 100 & 6 & 60 & 2 & 20 \\
\hline Senior lecturer & 0 & - & 0 & - & 2 & 20 \\
\hline Research fellow & 0 & - & 4 & 40 & 0 & - \\
\hline Total & 10 & - & 10 & - & 4 & - \\
\hline \multicolumn{7}{|l|}{ Type of employment } \\
\hline Permanent full time & 7 & 70 & 7 & 70 & 3 & 30 \\
\hline Temporary full time & 1 & 10 & 2 & 20 & 1 & 10 \\
\hline Contract & 0 & - & 0 & - & 0 & - \\
\hline Total & 8 & - & 9 & - & 4 & - \\
\hline \multicolumn{7}{|l|}{ Department } \\
\hline Business management & 2 & 20 & 2 & 20 & 1 & 10 \\
\hline Marketing & 0 & - & 0 & - & 1 & 10 \\
\hline Insurance \& Actuarial Science & 1 & 10 & 1 & 10 & 0 & - \\
\hline Accounting & 2 & 20 & 0 & & 0 & - \\
\hline IDS & 0 & - & 3 & 30 & 0 & - \\
\hline GSB & 0 & - & 0 & - & 2 & 20 \\
\hline Total & 10 & - & 9 & - & 4 & - \\
\hline
\end{tabular}

Note: Respondents could choose more than one option, or none at all; hence, the results do not tally with $N=10$.

IDS, Institute of Development Studies; GSB, Graduate School of Business; SME, small and medium enterprise.

keep their output in offices and at home, that is not an appropriate way of sharing the results. Surely, one cannot conduct research to keep the output in offices and at home, which suggests that perhaps the academic researchers have other motives for conducting the research studies or they have challenges in disseminating the results.

Results in Table 6 show what the researchers intended to do with their output. The results show that lecturers intended to use their research output for further studies, to explore promotional opportunities and to gain publicity. The implication is that disseminating the results to the recipients was not the primary motive. These results tally with views by Khatri et al. (2012) in Panda and Gupta (2014:8-9) that research may be related to publishing pressures for tenure and reputation and not out of genuine curiosity to explore and understand management.

The chi-square tests revealed significant relationships between the age range and the location of research output (0.003) and academic ranking (0.000) and the department
(0.002) and the researchers' intentions with their output. However, in all cases in Tables 1-4, no significant relationships were identified.

\section{Reasons for conducting research studies on small and medium enterprises by lecturers who had not disseminated their results}

Based on the reasons given in Table 2, the focus of research was in areas that have an impact on the viability and sustainability of SMEs such as failure and successes of SMEs, challenges faced by SMEs, business environment and SMEs, SME financing and integration of small and big businesses though ironically $41.67 \%$ of the SME owners had not been given feedback in more practicable ways. One then wonders how the SME owners would have achieved all these without receiving the aforementioned recommendations.

Beneficiaries of this study as shown in Table 3 were SME owners, policymakers and the donor community, respectively, with the owners of SMEs and policymakers receiving greater attention than the donor community. These results imply that the 
TABLE 4: Reasons for non-communication of results $(N=10)$.

\begin{tabular}{|c|c|c|c|c|c|c|c|c|}
\hline \multirow[t]{2}{*}{ Demographic variable } & \multicolumn{2}{|c|}{ I did not know where to find them } & \multicolumn{2}{|c|}{ My work is in the library } & \multicolumn{2}{|c|}{ They will get my results through policies } & \multicolumn{2}{|c|}{ They are too busy } \\
\hline & Frequency & Percentage & Frequency & Percentage & Frequency & Percentage & Frequency & Percentage \\
\hline \multicolumn{9}{|l|}{ Gender } \\
\hline Male & 4 & 40 & 1 & 10 & 3 & 30 & 4 & 40 \\
\hline Female & 0 & - & 1 & 10 & 3 & 30 & 1 & 10 \\
\hline Total & 4 & - & 2 & - & 6 & - & 5 & - \\
\hline \multicolumn{9}{|l|}{ Age range } \\
\hline 20 or younger & 0 & - & 1 & 10 & 1 & 10 & 0 & - \\
\hline $21-30$ & 0 & - & 0 & - & 0 & - & 0 & - \\
\hline $31-40$ & 0 & - & 1 & 10 & 4 & 40 & 4 & 40 \\
\hline $41-50$ & 0 & - & 0 & - & 0 & - & 0 & - \\
\hline 51 and above & 0 & - & 0 & - & 1 & 10 & 0 & - \\
\hline Total & 0 & - & 2 & - & 6 & - & 4 & - \\
\hline \multicolumn{9}{|l|}{ Highest level of education } \\
\hline Master's & 2 & 20 & 5 & 50 & 6 & 60 & 2 & 20 \\
\hline Total & 3 & - & 7 & - & 9 & - & 4 & - \\
\hline \multicolumn{9}{|l|}{ Academic ranking } \\
\hline Lecturer & 0 & - & 2 & 20 & 3 & 30 & 5 & 50 \\
\hline Senior lecturer & 0 & - & 0 & - & 0 & - & 2 & 20 \\
\hline Research Fellow & 2 & 20 & 1 & 10 & 3 & 30 & 5 & 50 \\
\hline Total & 2 & - & 3 & - & 6 & - & 12 & - \\
\hline \multicolumn{9}{|l|}{ Type of employment } \\
\hline Permanent full time & 0 & - & 2 & 20 & 4 & 40 & 5 & 50 \\
\hline Temporary full time & 0 & - & 3 & 30 & 1 & 10 & 0 & - \\
\hline Contract & 0 & - & 0 & - & 0 & - & 0 & - \\
\hline Total & 0 & - & 5 & - & 5 & - & - & - \\
\hline \multicolumn{9}{|l|}{ Department } \\
\hline Business management & 0 & - & 0 & & 2 & 20 & 0 & \\
\hline Marketing & 0 & - & 0 & & 0 & - & 0 & - \\
\hline Insurance \& Actuarial Science & 0 & - & 1 & 10 & 1 & 10 & 2 & 20 \\
\hline Accounting & 0 & - & 0 & - & 1 & 10 & 0 & - \\
\hline IDS & 0 & - & 0 & - & 2 & 20 & 0 & - \\
\hline GSB & 0 & - & 2 & 20 & 0 & - & 0 & - \\
\hline Total & 1 & - & 4 & - & 6 & - & 4 & - \\
\hline
\end{tabular}

Note: Respondents could choose more than one option, or none at all; hence, the results do not tally with $N=10$.

IDS, Institute of Development Studies; GSB, Graduate School of Business.

researchers were aware that owners of SMEs stood to benefit more from their studies and that the policymakers were responsible for creating a conducive environment. What is important is to get the proper policies in place first, which will then drive the businesses towards success and this can only happen if the results are conveyed to the policymakers. Academic researchers should not forget that they have an obligation to disseminate their output to the respondents that they collect data from who might not have access to aforementioned channels. In order to gain entry into university libraries, a membership card is required. To have access to online publications, one needs to be in possession of appropriate equipment, have Internet connectivity and be equipped with relevant knowledge and skills to correctly interpret the findings.

\section{Reasons for lecturers' non-dissemination of results and what they intended to do with their research output}

Table 4 shows researchers' reasons for not communicating the findings, which ranged from conveying the results through policies, getting results from the library and not knowing where to find the beneficiaries. Master's holders indicated that the recipients would get their results through policies $(60 \%)$ and in the libraries (50\%). Forty per cent of the male respondents indicated that they did not know where to find the recipients. These results corroborate views by Stepherson et al. (2014:31) that although universities conduct a great deal of research on SMEs, the outputs of such research seem not to reach the intended beneficiaries. Academics are the ones expected to research and inform the intended beneficiaries of the findings through practicable means but when the output is kept in the offices and homes, then the output ceases to have value for SME owners and policymakers who are the intended recipients. This is why the researcher earlier on raised the question of whether these research studies were conducted to benefit the purported beneficiaries or the ones listed as beneficiaries were actually left out in the cold.

Viewed from one perspective, these results resonate with views by Stepherson et al. (2014:16) on non-communication of results. On the other hand, there is conflict with views by 
TABLE 5: Location of research studies by respondents who did not convey their results $(N=10)$.

\begin{tabular}{|c|c|c|c|c|c|c|c|c|c|}
\hline \multirow[t]{2}{*}{ Demographic variable } & \multicolumn{2}{|c|}{ University library } & \multicolumn{2}{|c|}{ My office } & \multicolumn{2}{|c|}{ Online } & \multicolumn{2}{|c|}{ At home } & \multirow[t]{2}{*}{ Sig. } \\
\hline & Frequency & Percentage & Frequency & Percentage & Frequency & Percentage & Frequency & Percentage & \\
\hline Gender & & & & & & & & & - \\
\hline Male & 2 & 20 & 7 & 70 & 5 & - & 3 & 30 & - \\
\hline Female & 1 & 10 & 1 & 10 & 4 & - & 0 & - & - \\
\hline Total & 3 & - & 8 & - & 9 & - & 3 & - & - \\
\hline \multicolumn{10}{|l|}{ Age range } \\
\hline 20 or younger & 1 & 10 & 0 & - & 0 & - & 0 & - & - \\
\hline $21-30$ & 0 & - & 0 & - & 0 & - & 2 & 20 & 0.003 \\
\hline $31-40$ & 0 & - & 7 & 70 & 5 & - & 0 & - & - \\
\hline $41-50$ & 1 & 10 & 0 & - & 3 & - & 0 & - & - \\
\hline 51 and above & 1 & 10 & 1 & 10 & 1 & - & 1 & 10 & - \\
\hline Total & 3 & - & 8 & - & 9 & - & 3 & - & - \\
\hline \multicolumn{10}{|l|}{ Highest level of education } \\
\hline Master's & 2 & 20 & 5 & 50 & 8 & - & 0 & - & - \\
\hline $\mathrm{PhD}$ & 1 & 10 & 2 & 20 & 1 & - & 3 & 30 & - \\
\hline Total & 3 & - & 7 & - & 9 & - & 3 & - & - \\
\hline \multicolumn{10}{|l|}{ Academic ranking } \\
\hline Lecturer & 3 & 30 & 7 & 70 & 4 & - & 4 & 40 & - \\
\hline Senior lecturer & 0 & - & 0 & - & 2 & - & 0 & - & - \\
\hline Research fellow & 0 & - & 1 & 10 & 2 & - & 0 & - & - \\
\hline Total & 3 & - & 8 & - & 8 & - & 4 & - & - \\
\hline \multicolumn{10}{|l|}{ Type of employment } \\
\hline Permanent full time & 3 & 30 & 6 & 60 & 8 & - & 0 & - & - \\
\hline Temporary full time & 0 & - & 2 & 20 & 0 & - & 1 & 10 & - \\
\hline Contract & 0 & - & 0 & - & 0 & - & 0 & - & - \\
\hline Total & 3 & - & 8 & - & 8 & - & 1 & - & - \\
\hline \multicolumn{10}{|l|}{ Department } \\
\hline Business management & 0 & - & 1 & 10 & 2 & - & 1 & 10 & - \\
\hline Marketing & 0 & - & 0 & - & 0 & - & 0 & - & - \\
\hline Banking & 0 & - & 2 & 20 & 1 & - & 0 & - & - \\
\hline Finance & 1 & 10 & 3 & 30 & 1 & - & 0 & - & - \\
\hline Insurance \& Actuarial Science & 0 & - & 1 & 10 & 0 & - & 0 & - & - \\
\hline Accounting & 0 & - & 0 & - & 0 & - & 2 & 20 & - \\
\hline IDS & 0 & - & 1 & 10 & 2 & - & 0 & - & - \\
\hline GSB & 0 & - & 0 & - & 4 & - & 0 & - & - \\
\hline Total & 1 & - & 8 & - & 10 & - & 3 & - & - \\
\hline
\end{tabular}

Note: Respondents could choose more than one option, or none at all; hence, the results do not tally with $N=10$.

IDS, Institute of Development Studies; GSB, Graduate School of Business.

Okonofua (2008) cited in Nwabueze et al. (2010:1) who sees universities as key institutions in the process of social change and development. If the results are not communicated to the SMEs, their development is delayed, as postulated by Mutwiri (2014:14). Findings of this study show that research in this new science of entrepreneurship had been conducted and knowledge that could capacitate SMEs to achieve viability and sustainability had been generated but not all respondents had shared these findings with the SMEs for practical use.

\section{The level of awareness by the lecturers on the importance of communicating research results and when research can be made beneficial}

The above objective was addressed through open-ended questions on when research output is considered to be beneficial and how research results can be made to be beneficial. The following verbatim statements attest to the responses that were obtained from all the 24 respondents and they are grouped according to similarities.

\section{When research output is disseminated to the intended beneficiaries}

'When the results are disseminated to the intended beneficiaries.' (Participant 1, male, lecturer)

The majority of the respondents felt that research output is beneficial when it is disseminated to the intended beneficiaries who can then use it. This is a reflection of lecturers' awareness of the importance of distributing their research to beneficiaries, although some of them had not. These findings resonate with views by Meriam and Tisdell (2016:290), Turale (2011:2) and McGrath (2016:3) that results only make a meaningful contribution when they are shared.

Another theme that emerged from the analysis was that research is beneficial when it contributes to the body of literature as shown by the following statements:

'When other researchers use the results as a base for further research.' (Participant 2, female, lecturer)

'When it contributes to literature and helps upcoming researchers.' (Participant 3, male, lecturer) 
TABLE 6: Intentions of respondents who did not disseminate their output $(N=10)$.

\begin{tabular}{|c|c|c|c|c|c|c|c|c|c|c|c|c|}
\hline \multirow{3}{*}{$\begin{array}{l}\text { Demographic } \\
\text { variable }\end{array}$} & \multicolumn{4}{|c|}{ Gain publicity } & \multicolumn{4}{|c|}{ Use it for future studies } & \multicolumn{4}{|c|}{ Explore promotion opportunities } \\
\hline & \multicolumn{2}{|c|}{ Agree } & \multicolumn{2}{|c|}{ Strongly agree } & \multicolumn{2}{|c|}{ Agree } & \multicolumn{2}{|c|}{ Strongly agree } & \multicolumn{2}{|c|}{ Agree } & \multicolumn{2}{|c|}{ Strongly agree } \\
\hline & Frequency & Percentage & Frequency & Percentage & Frequency & Percentage & Frequency & Percentage & Frequency & Percentage & Frequency & Percentage \\
\hline \multicolumn{13}{|l|}{ Gender } \\
\hline Male & 2 & 20 & 2 & 20 & 4 & 40 & 4 & 40 & 3 & 30 & 4 & 40 \\
\hline Female & 3 & 30 & 1 & 10 & 3 & 30 & 3 & 30 & 1 & 10 & 4 & 40 \\
\hline Total & 5 & - & 3 & - & 7 & - & 7 & - & 4 & - & 8 & - \\
\hline \multicolumn{13}{|l|}{ Age range } \\
\hline 20 or younger & 1 & 10 & 0 & - & 1 & 10 & 0 & - & 1 & 10 & 0 & - \\
\hline $21-30$ & 0 & - & 0 & - & 0 & - & 2 & 20 & 0 & - & 0 & - \\
\hline $31-40$ & 3 & 30 & 2 & 20 & 7 & 70 & 5 & 50 & 1 & 10 & 4 & 40 \\
\hline $41-50$ & 0 & - & 0 & - & 2 & 20 & 3 & 30 & 2 & 20 & 2 & 20 \\
\hline 51 and above & 1 & 10 & 0 & - & 0 & - & 0 & - & 0 & & 2 & 20 \\
\hline Total & 5 & - & 2 & - & 10 & - & 10 & - & 4 & - & 8 & - \\
\hline \multicolumn{13}{|l|}{ Highest level of education } \\
\hline Master's & 5 & 50 & 2 & 20 & 9 & 90 & 9 & 90 & 4 & 40 & 6 & 60 \\
\hline $\mathrm{PhD}$ & 0 & - & 1 & 10 & 1 & 10 & 1 & 10 & 0 & & 2 & 20 \\
\hline Total & 5 & - & 3 & & 10 & & 10 & & 4 & & 8 & \\
\hline \multicolumn{13}{|l|}{ Academic ranking } \\
\hline Lecturer & 2 & 20 & 3 & 30 & 6 & 60 & 10 & 10 & 2 & 20 & 5 & 50 \\
\hline Senior lecturer & 0 & - & 0 & - & 2 & 20 & 0 & - & 2 & 20 & 0 & - \\
\hline Research fellow & 5 & 50 & 3 & 30 & 2 & 20 & 0 & - & 4 & - & 3 & 30 \\
\hline Total & 7 & - & 6 & - & 10 & - & 10 & - & 8 & - & 8 & - \\
\hline \multicolumn{13}{|l|}{ Type of employment } \\
\hline Permanent full time & 3 & 30 & 2 & 20 & 9 & 90 & 8 & 80 & 4 & 40 & 7 & 70 \\
\hline Temporary full time & 1 & 10 & 1 & 10 & 0 & - & 0 & - & 0 & - & 0 & - \\
\hline Contract & 0 & - & 0 & - & 0 & - & 0 & - & 0 & - & 0 & - \\
\hline Total & 4 & - & 3 & - & 9 & - & 8 & - & 4 & - & 7 & - \\
\hline \multicolumn{13}{|l|}{ Department } \\
\hline $\begin{array}{l}\text { Business } \\
\text { management }\end{array}$ & 2 & 20 & 0 & - & 1 & 10 & 2 & 20 & 0 & - & 2 & 20 \\
\hline Marketing & 0 & - & 0 & - & 0 & - & 1 & 10 & 0 & - & 1 & 10 \\
\hline Banking & 0 & - & 1 & 10 & 1 & 10 & 2 & 20 & 1 & 10 & 1 & 10 \\
\hline Finance & 0 & - & 0 & - & 3 & 30 & 2 & 20 & 0 & - & 1 & 10 \\
\hline Insurance & 1 & 10 & 1 & 10 & 1 & 10 & 1 & 10 & 1 & 10 & 0 & - \\
\hline Accounting & 0 & - & 0 & - & 0 & - & 1 & 10 & 0 & - & 0 & - \\
\hline IDS & 2 & 20 & 0 & - & 2 & 20 & 1 & 10 & 0 & - & 2 & 20 \\
\hline GSB & 0 & - & 0 & - & 2 & 20 & 0 & - & 2 & 20 & 0 & - \\
\hline Total & 5 & - & 2 & - & 10 & - & 10 & - & 4 & - & 7 & - \\
\hline
\end{tabular}

Note: Respondents could choose more than one option, or none at all; hence, the results do not tally with $N=10$.

IDS, Institute of Development Studies; GSB, Graduate School of Business.

These views are in tandem with those of Kavulya (2004:3), Mutwiri (2014:1) and Okonofua (2008) cited in Nwabueze et al. (2010:1) that universities produce new knowledge through research and serve as conduits for the transfer, adaptation and dissemination of generated knowledge.

Some participants felt that research output was beneficial when it is used for the intended purposes.

'When it is applied to specific reasons.' (Participant 4, male, lecturer)

'When it is shared and intended beneficiaries are given feedback of the research results.' (Participant 5, male, lecturer)

The author of this study shares similar sentiments expressed earlier on that as long as research output is not used for the purposes that it was intended to, it ceases to have value.

Also, to emerge as one of the sub-themes was that research output is beneficial when the recommendations are implemented. The following statements bear testimony to the aforementioned.

'Research is beneficial when the intended beneficiaries implement the research findings and recommendations.' (Participant 6, male, lecturer)

'When results are availed to recipients who implement them.' (Participant 7, male, lecturer)

'When recipients use it in their industries.' (Participant 8, female, lecturer)

'When it can be applied practically in the real world.' (Participant 9 , male, lecturer)

'When the intended recipients use the results to amend existing strategies.' (Participant 10, male, lecturer)

'When the results are converted into products that will benefit the communities and research at large.' (Participant 11, female, lecturer)

The responses given are in line with results from Lokkegaard's (2018:145) study that for SMEs to be able to implement 
scientific knowledge to their own situations and issues, they need scientific knowledge to be practically oriented and usable to solve specific needs. What is paramount is that when researchers convey the results to SME owners for implementation, they must refrain from using the jargon and rigour that is associated with academics as postulated by Lang (2003:3) and Panda and Gupta (2014:2).

\section{When value has been added to the lives of the beneficiaries}

Stepherson et al. (2014:37) contended that research should be a vehicle for change and should address the urgent needs of society. The participants concur this as conveyed in the following statements:

'When it is shared with the beneficiaries of the study and has a practical impact on the community and not just for academic purposes.' (Participant 12, male, lecturer)

'When it is usable by targeted communities.' (Participant 13, female, lecturer)

'When it contributes to economic growth.' (Participant 14, male, lecturer)

The author agrees that research output should enhance livelihoods and benefit the communities in which the studies are conducted. While universities are mandated for teaching and learning, some of the material they use is generated from the same communities and should be given back to them in the form of advice and solutions to the political, economic, social, technological and legal challenges (PESTL) that they face in their day-to-day lives. Similarly, when research output on SMEs is communicated to the SME owners for implementation, there are bound to be positive changes in the operations of their businesses.

\section{When it informs policymakers}

'Research is useful when it is in the public domain and is being used by practitioners to improve on their practices and when it influences policy in the area of research, for example, SME policy.' (Participant 15, male, lecturer)

'When it avails new information to the government which helps improve decision making.' (Participant 16, male, lecturer)

'If the results have policy implications and findings can help to transform communities and the country as a whole.' (Participant 17 , male, lecturer)

The views of the respondents are quite relevant to SMEs. For SMEs to be viable and sustainable, it starts with a conducive and supportive environment. Creating a conducive environment is one of the government's obligations and most often researchers list policymakers as beneficiaries for primarily the aforementioned reason. In this regard, research output serves its purpose when it influences the policymakers in coming up with decisions that will benefit all the stakeholders affected by the policies that have been crafted. These findings are in tandem with views by Geuna and Muscio (2009:93) that dissemination continues to be a strategic issue not only for universities but also for decision-makers.
It would be inadequate to focus on when research output is beneficial without considering ways in which it can be made beneficial. The statements that follow explain how research output can be made beneficial.

\section{How research output can be made beneficial?}

The respondents mentioned that research output is beneficial when findings are communicated through the media, workshops, seminars, conferences, publications, lobbying the government and engaging the stakeholders. The participants' responses are elaborated in the verbatim statements that follow.

'It should be synthesised and published in the local media so that it can be widely disseminated.' (Participant 18, female, lecturer)

'By serialising research output in public media such as televisions and newspapers.' (Participant 19, female, lecturer)

'Through dissemination of the output using workshops within the communities and not necessarily through academic conferences.' (Participant 20, male, lecturer)

'Via government sponsored workshops.' (Participant 21, male, lecturer)

'Through publications and when it is availed in university libraries.' (Participant 22, male, lecturer)

'Sharing research outputs within a reasonable completion time would help the stakeholders with making informed decisions.' (Participant 23, male, lecturer)

The responses are an indication that lecturers were quite wary of the fact that there should be wide coverage of the disseminated results and that communities should be involved. Although the respondents mentioned that the communities should also be engaged and not necessarily through academic conferences, they did not clearly spell out how the communities would be mobilised for these workshops. Some of the responses though lack contextual relevance. For example, that research output should be availed in libraries makes the assumption that all SME owners have access to the libraries which might not necessarily be so. The same with the issue of television as a form of communication: while some SME owners even in rural areas have television sets, it is not all; hence, it is important to factor in the needs, capabilities and capacities of beneficiaries when deciding how research output can be made beneficial.

The response on sharing output within a reasonable completion time warrants being highlighted because the participants were aware of the need to disseminate their findings within a reasonable completion time. While it might not be clear what they meant by 'a reasonable completion time', what is important is that they were aware that time was an important factor as posited by Panda and Gupta (2014:12); that in order for research to be useful to practitioners, the insights from the research should be available for use in time.

'Through sharing and collaborating with industry partners and through various forums. Through commercialisation of the research output.' (Participant 24, male, lecturer)

Some of the respondents mentioned that research output can be beneficial when it is commercialised. 
What is implied by this statement is that research output should only be made available to those who can pay for it. What the researcher forgets is that when he or she collected the data, he or she was not made to pay and that calls for giving back to the community without payment as well.

\section{Recommendations}

For any research study to have a positive impact on the intended beneficiaries, researchers should disseminate results for implementation. However, in the absence of communication of the findings to the targeted recipients, one wonders who the real beneficiaries are. In light of the above results, the study made the following recommendations in accordance with the objectives.

\section{Intended beneficiaries}

Although lecturers are not forced to give feedback to the respondents, it is always good to give back to the community that you will have obtained data from. Giving feedback would not only be an act of social responsibility but also show an understanding of the obligations that academics are creating for themselves by nominating targeted respondents for their studies.

\section{Dissemination of research output and revision of promotion policies by universities}

While readers might be quick to point out that researchers might have acted socially irresponsibly by not disseminating their results, such a scenario calls for a more thorough investigation. There is need to determine why these researchers who were aware that research output should be disseminated would have embarked on research studies relating to important institutions like SMEs, and fail to disseminate their findings for practical use. These results could be an indication of underlying challenges. There is a need for responsible authorities to intensify efforts to encourage all lecturers to communicate their results to the intended beneficiaries. Lecturers can utilise community engagements to communicate their findings for implementation.

The study recommends that before an application for promotion is approved, there should not only be evidence of the number of research articles that the academic has written but also of communication of research output for practical use. This calls for a shift in the university policy regarding promotion. Currently, as long as the number of stipulated articles has been achieved, everything is in order as the aspect of dissemination of results is not captured. There is a need to incorporate the dissemination of results as part of research.

\section{Implications for policymakers that fund universities}

When the sponsors see the impact of research output on beneficiaries' lives, they are bound to increase funding. In this regard, researchers should disseminate their findings for practical use so that the viability and sustainability of SMEs is enhanced and other researchers benefit. Policymakers can use findings to create better communities.

\section{Areas of focus of research}

It is recommended that lecturers should not only identify research gaps in the literature but should also consult the owners so as to conduct studies based on SME owners' needs. Consultations with users of output would certainly bring about meaningful change. Several studies could be carried out to investigate why academics in the university under study had not shared their results and what happens in other universities in Zimbabwe and beyond its borders regarding the deficiency of research in this area.

\section{Conclusions}

Based on the results, this study made the following conclusions.

First and most importantly, it can be concluded that in this particular study, the academics and their institution, respectively, were the ones to benefit from the studies. Academics benefitted in terms of completed degree programmes and reasons that they gave of using their output for future studies, to explore promotion opportunities and to gain publicity. The institution gained through receiving qualified personnel. The purported beneficiaries, that is, the SME owners and policymakers, seem to have been forgotten.

Secondly, the reasons that lecturers gave for conducting studies on SMEs were noble such as successes and failures of SMEs, challenges faced by SMEs, business environment and integration of small and big businesses. These areas contribute to the viability and sustainability of SMEs. However, the weakness was in the non-dissemination of results. While it can be argued that it is not mandatory for lecturers to disseminate their results but as an act of corporate social responsibility; as agents of transformation and as a sign of appreciation for the respondents' time, they should communicate the results to the intended beneficiaries.

Thirdly, the reasons given by the researchers that results would be disseminated through policies, the library and that respondents were too busy and that the researchers did not know where to get the beneficiaries do not show the researchers' concern for their beneficiaries.

Fourthly, although researchers nominated beneficiaries for their studies, it turned out that they did not benefit as much as it was expected. In this particular study, for example, SME owners were supposed to be the main benefactors but the results were not communicated to them for implementation. Instead, reasons such as dissertations were in the offices and at home were given. What the researchers overlooked was the accessibility issue and the context of their beneficiaries; how many of the targeted beneficiaries would gain access into their offices and homes? 
Fifthly and finally, the study revealed that lecturers were aware of when research output was beneficial. The study was a success in that it unmasked the need for a thorough research on why lecturers had not communicated their results for practical use. The results have provided insights for further investigations of what happens in other institutions. This is a wake-up call to the university authorities to come up with ways of addressing non-dissemination of output.

\section{Acknowledgements Competing interests}

The author declares no competing interests with regard to the writing of this article.

\section{References}

Bauman, A.E., Nelson, D.E., Pratt, M.M. \& Victor, S.S., 2017, 'Dissemination of physical activity evidence, programs, policies, and surveillance in the International public health arena', American Journal of Preventive Medicine 31(4S), S57-S65.

Bouazza, A.B., 2015, 'Challenges of SMEs in Algeria', International Journal of Economics, Commerce and Management 3(2), 1-16.

Brennan, J., King, R. \& Lebeau, Y., 2004, The role of universities in the transformation of societies: An international research project, Synthesis Report, Centre for Higher Education Research and Information, viewed 10 March 2016, from https://www. open.ac.uk/cheri/documents/transf-final-report.pdfs.

Bryman, A., 2012, Social research methods, 4th edn., University Press, Oxford.

Bryman, A., Bell, E., Hirschsohn, P., Dos Santos, A., Dutoit, J., Masenge, A. et al., 2017, Research methodology. Business and management contexts, 7th edn., Oxford University Press.

Cooper, D.R. \& Schindler, P., 2008, Business research methods, McGraw Hill, Irwin, Singapore.

Fry, J., Oppenheim, C., Creaser, C., Johnson, W., Summers, M., White, S. et al., 2009 Communicating knowledge: How and why researchers publish and disseminate research findings, Supporting Paper 2: Report of focus group findings, Research Information Network, viewed 13 June 2016, from www.rin.ac.uk.

Geuna, A. \& Muscio, A., 2009, 'The governance of university knowledge transfer: A critical review of the literature. Minerva: A review of science', Learning and Policy 47(1), 93-114.

Gombarume, F.B. \& Mavhundutse, S., 2014, 'Challenges faced by small to medium enterprises: A case study of Chitungwiza, Zimbabwe', Greener Journal of Business and Management Studies 4(4), 103-107. https://doi.org/10.15580/ GJBMS.2014.4.102113910
Kavulya, J.M., 2004, A study of their practices and performance, University Libraries in Kenya, pp. 1-236, viewed 13 March 2016, from http://edoc.hu-berlin.de/ dissertation/Kavulya-joseph-muema-2004-02-19/PDF/Kavul.

Kongolo, M., 2010, 'Job creation versus job shedding and the role of SMEs in economic development', African Journal of Business Management 4(11), 2288-2295.

Krejcie, R.V. \& Morgan, D.W., 1970, 'Determining sample size for research activities', Educational and Psychological Measurement 30,607-610, viewed 15 April 2016 from home.kku.ac.th/sompong/guest_speaker/KrejcieandMorgan_article.pdf.

Lang, M., 2003, Communicating academic research findings to IS professionals: An analysis of problems, viewed 17 April 2016, from http://www.inform.nu/Articles/ Vol6/v6, 021-029pdf.

Lokkegaard, S., 2018, Disseminating scientific knowledge to small and medium sized enterprises, Aalborg University, Aalborg University Press, Aalborg, Denmark.

Macoubrie, J. \& Harrison, C., 2013, Value-Added research dissemination framework, OPRE Report. Office of Planning, Research and Evaluation and Evaluation, (OPRE) Administration for children and families, US Department of Health and Human Services, viewed 02 May 2016, from http://www.acf.hhs.gov/programs/opre/ Services, view.
index.html.

McGrath, B., 2016, A guide to ensuring wide dissemination and lasting impact for your research, The Atlantic Philanthropies, viewed 10 February 2018, from http://www. atlanticphilantropies.org/app/uploads/2016/03/Research-Dissemination-G:1-12.

Merriam, S.B. \& Tisdell, E.J., 2016, Qualitative research: A guide to design and implementation, Jossey-Bass, A Wiley Brand, San Francisco, CA.

Munanga, E., 2013, 'Financial challenges faced by retail SMEs operating in a multicurrency environment: A case of Gweru urban, Zimbabwe', Asian Economic and Financial Review 3(3), 377-388.

Mutwiri, C.M., 2014, 'Challenges facing academic staff in adopting open access outlets for disseminating research findings in selected university libraries in Kenya', A thesis submitted for the award of the Degree of Doctor of Philosophy (PhD) Library and Information Science in the School of Education of Kenyatta University.

Nwabueze, A., Anyira, I.E., Ivwighreghweta, O. \& Onoride, O.K., 2010, The role and responsibility of the library in consolidating research in Nigerian private responsibility of the library in consolidating research in Nigerian private 17 April 2016, from http://digitalcommons.unl.edu/libphilprac/415.

Oronje, R.N., 2006, 'Challenges faced by African organisations in knowledge sharing: The case of the African population and health research centre', APHRC, KM $4 D$ Journal 2(1), 78-87, viewed 10 June 2016, from http://journal.km4dev.org/index. $\mathrm{php} / \mathrm{km} 4 \mathrm{dj} /$ article/viewFile/54/96\%20orange, \%20R\%20.

Panda, A. \& Gupta, R.J., 2014, 'Making academic research more relevant: A few suggestions', II MB Management Review 26, 156-169, viewed 10 June 2016, from http://www.sciencedirect.com/science/journal/09703896/26/3.

Stepherson, D., Calda, V. \& Javier, E.S., 2014, 'Building communication highways for research dissemination', The Global Journal of Management and Business Research: Administration and Management 14(5), 31-37.

Tinarwo, R., 2016, 'An investigation into the challenges faced by small to medium enterprises in Zimbabwe: A case of Gazaland market', IOSR Journal of Business and Management (IOSR-JBMO) 18(9), 148-153. https://doi.org/10.9790/487X-180902148153

Tshili, N., 2015, 'Varsities rotten: "Academics failing to make an impact on developmental issues"', Chronicle, viewed 18 December 2015, from www.chronicle.co.zw/varsitiesrotten-prof-moyo-academics-failing-to-make-an-impact.

Turale, S., 2011, 'The dissemination of research findings and translation into practice', Journal of Nursing Science 29(2), 8-11. 